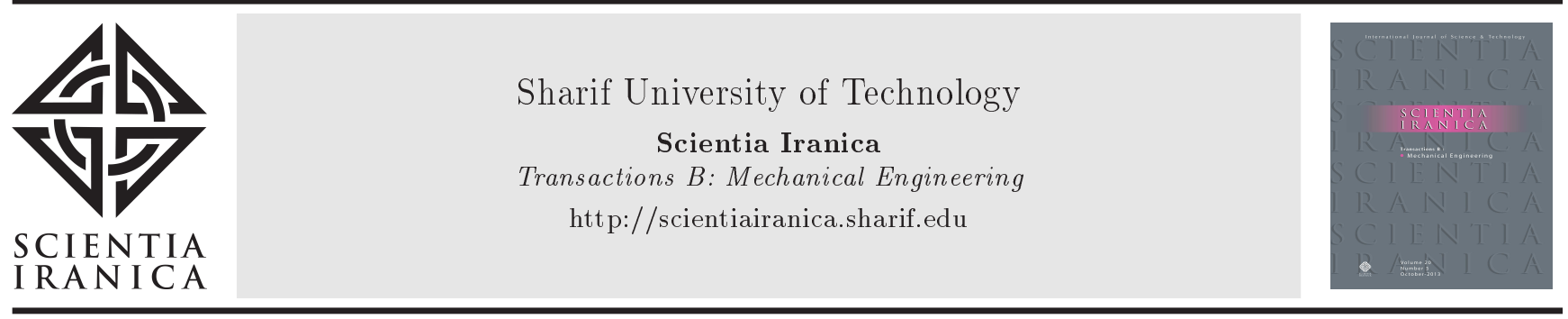

Research Note

\title{
Numerical investigation into flow and mixed convective heat transfer of non-Newtonian impinging slot jets
}

\author{
R. Gharraei*, A. Vejdani, and L. Sasani \\ Department of Mechanical Engineering, Azarbaijan Shahid Madani University, Tabriz, P.O. Box 53714-161, Iran.
}

Received 28 May 2016; received in revised form 18 February 2017; accepted 1 July 2017

\section{KEYWORDS}

Non-Newtonian fluid;

Heat transfer;

OpenFOAM;

Recirculation;

Richardson number.

\begin{abstract}
Mixed convection heat transfer of non-Newtonian impinging slot jets was investigated numerically in this study. The simulation was performed using a temperaturedependent power-law viscosity model. The results showed that, for high Richardson numbers, a recirculation zone was created in the vicinity of impingement wall which prevents the jet stream from penetration into near wall region and decreases the Nusselt number around the stagnation point. The effects of jet-to-plate spacing, inlet Peclet number, and jet inlet width on the flow structure and heat transfer characteristics of impinging jet were studied using the numerical results. By decreasing jet-to-plate spacing and jet inlet width and increasing inlet Peclet number, the flow reversal in the vicinity of heated wall disappeared, and the local Nusselt number increased as a result of deeper penetration of jet stream into the near wall region. Furthermore, the results indicate that the maximum local and average Nusselt numbers belong to the shear-thinning jets with minimum inlet width and minimum jet-to-plate spacing.
\end{abstract}

(C) 2018 Sharif University of Technology. All rights reserved.

\section{Introduction}

Considering the importance of impinging jets for cooling heated surfaces, a large variety of techniques have been used to increase the heat transfer between jet and heated surface. Application of impinging jets to mixed convection regime is one of the most efficient methods for cooling hot surfaces. The numerical and experimental studies on fluid flow and heat transfer characteristics of confined slot jets were reported in

\footnotetext{
*. Corresponding author. Tel.: +984131452576;

Fax: +984134327566

E-mail addresses: gharraei@azaruniv.ac.ir (R. Gharraei);

amirvejdany@gmail.com (A.Vejdani);

sasany.leila@gmail.com (L.Sasani).
}

doi: $10.24200 /$ sci.2017.4345 literature [1-5]. Aldabbagh and Mohammad [6] investigated the flow and heat transfer characteristics of a single-square jet impinging on a heated flat plate in the mixed convection regime. Their study indicated that, for dimensionless jet-to-plate spacing of 0.25 , the flow structure is independent of Richardson number. Furthermore, it was observed that for a given Richardson number, increasing the Reynolds number leads to increasing heat transfer rate. Poh and Kumar [7] studied the heat transfer of a single axisymmetric laminar impinging jet for various carboxymethyl cellulose (CMC) aqueous solutions, behaving as the power-law fluids. The effects of the jet Reynolds number, inlet velocity, and jet-to-plate spacing on the heat transfer characteristics were investigated. It was found that, for the same Reynolds number, the fluids with lower power-law index have higher Nusselt number due to 
the higher inlet velocity.

Chatterjee et al. [8] investigated the flow and heat transfer of an inelastic Carreau fluid axisymmetric impinging jet. Their results revealed off-stagnation maxima in Nusselt number distribution on the impingement wall which disappeared for Newtonian and shear-thickening fluids. Location and magnitude of maxima depend on dimensionless jet-to-plate spacing, and heat transfer maxima were seen even for Newtonian jets for very low aspect ratios. Cavadas et al. [9] studied the flow created by impingement of a non-Newtonian laminar slot jet on a flat plate confined by sloping walls. Their study indicated the presence of recirculation zones attached to sloping walls whose sizes increase with Reynolds number. Wang and Chen [10] investigated mixed convection heat transfer for non-Newtonian fluid flow over wavy surface. The numerical results indicated higher total heat transfer rate for the wavy surface than for the flat plate. Moreover, for a given Richardson number, the increase of generalized Prandtl number and wavelength of wavy surface leads to heat transfer enhancement. Lee et al. [11] studied flow and heat transfer characteristics of a laminar milli-scale slot jet which impinges on an isothermal plate, eventually. It was found that for all of specified Reynolds numbers and aspect ratios, local Nusselt number decreases by lateral distance from the stagnation point. Their results showed the sensitivity of Nusselt number to momentum and thermal boundary layer, as well as the restrictions on near-wall temperature gradients. Kumari et al. [12] investigated the laminar free convection of a non-Newtonian powerlaw fluid over an isothermal wavy surface. They studied the effects of the power-law index, wavelength of surface waviness, and Prandtl number on the velocity and temperature fields. Their results showed that the local Nusselt number varies periodically along the wavy surface, and the wavelength of local Nusselt number is half of wavelength of wavy surface. Sivasamy et al. [13] studied the jet impingement cooling of a constant heat flux horizontal plate. Their results were presented for a confined porous channel in the mixed convection regime with various parameters. They concluded that, for high values of Peclet number, an increase in Rayleigh number or jet width and also a decrease in jet-to-plate spacing augment the heat transfer.

Review of the literature reveals that despite investigating various related studies, there is not any reported study on the non-Newtonian impinging slot jets in the mixed convection regime. Therefore, the main purpose of this study is to investigate the effects of buoyancy on the flow structure and heat transfer characteristics of non-Newtonian impinging slot jets. Decreasing jet-to-plate spacing, increasing inlet Peclet number, and reducing the jet inlet width facilitate the concentration of the momentum flux on the stagnation point; in addition, the effects of these changes on the flow and heat transfer characteristics have been studied through the numerical simulations.

\section{Governing equations}

Figure 1 presents the computational domain to analyze a two-dimensional confined impinging jet. Considering the Boussinesq approximation for buoyancy force and using a refined version of power-law viscosity model $[14,15]$ for implementing the thermal effects on the viscosity term, the governing equations for the laminar flow of incompressible non-Newtonian fluid jet can be written as follows [10]:

$$
\begin{aligned}
& \frac{\partial u}{\partial x}+\frac{\partial v}{\partial y}=0 \\
& \rho\left(u \frac{\partial u}{\partial x}+v \frac{\partial u}{\partial y}\right)=-\frac{\partial P}{\partial x}+K e^{\left(T_{\text {ref }} / T\right)}\left(2 \frac{\partial}{\partial x}\left(J \frac{\partial u}{\partial x}\right)\right. \\
& \left.+\frac{\partial}{\partial y}\left(J\left(\frac{\partial u}{\partial y}+\frac{\partial v}{\partial x}\right)\right)\right) \\
& \rho\left(u \frac{\partial v}{\partial x}+v \frac{\partial v}{\partial y}\right)=-\frac{\partial P}{\partial y}+\rho g \beta\left(T-T_{\infty}\right) \\
& +K e^{\left(T_{\mathrm{ref}} / T\right)}\left(2 \frac{\partial}{\partial y}\left(J \frac{\partial v}{\partial y}\right)\right. \\
& \left.+\frac{\partial}{\partial x}\left(J\left(\frac{\partial u}{\partial y}+\frac{\partial v}{\partial x}\right)\right)\right) \\
& \rho C_{p}\left(u \frac{\partial T}{\partial x}+v \frac{\partial T}{\partial y}\right)=K_{f}\left(\frac{\partial^{2} T}{\partial x^{2}}+\frac{\partial^{2} T}{\partial y^{2}}\right), \\
& J=\left\{2\left(\frac{\partial u}{\partial x}\right)^{2}+\left(\frac{\partial v}{\partial y}\right)^{2}+\left(\frac{\partial u}{\partial y}+\frac{\partial v}{\partial x}\right)^{2}\right\}^{(n-1) / 2}
\end{aligned}
$$

Dimensionless variables are defined as follows:

$$
\begin{aligned}
& D^{*}=\frac{d}{D}, \quad A_{y}=\frac{L_{y}}{D}, \quad X=\frac{x}{D}, \quad Y=\frac{y}{D}, \\
& \theta=\frac{T-T_{w}}{T_{\text {jet }}-T_{w}}, \quad U=\frac{u}{W_{\text {jet }}}, \quad V=\frac{v}{W_{\text {jet }}} .
\end{aligned}
$$

Reynolds, Prandtel, and Peclet numbers are as follows [16]:

$$
\begin{aligned}
& \operatorname{Re}=\frac{\rho W_{\text {jet }}^{2-n} D^{n}}{K}, \quad \operatorname{Pr}=\frac{C_{p} K W_{\text {jet }}^{n-1} D^{1-n}}{K_{f}}, \\
& \operatorname{Pe}=\operatorname{Re} \operatorname{Pr}=\frac{\rho C_{p} W_{\text {jet }} D}{K_{f}} .
\end{aligned}
$$


Richardson and Grashof numbers are as follows [10]:

$$
\mathrm{Ri}=\frac{G r}{\operatorname{Re}^{2}}, \quad \mathrm{Gr}=\frac{g \beta\left(T_{w}-T_{\mathrm{jet}}\right) \rho^{2} W_{\mathrm{jet}}^{2(1-n)} D^{1+2 n}}{K^{2}} .
$$

The local Nusselt number and local convective heat transfer coefficient are defined as follows:

$$
\mathrm{Nu}=\frac{h D}{K_{f}}, \quad h=\frac{q_{w}^{\prime \prime}}{T_{w}-T_{\mathrm{jet}}} .
$$

\section{Numerical method}

The open-source CFD package, OpenFOAM (Open Field Operation And Manipulation), was employed to solve the governing equations. This code employs finite volume method for the discretization of partial differential equations. SIMPLE algorithm [17] was used for handling the pressure-velocity coupling. The effect of temperature on effective viscosity was implemented by developing a new temperature-dependent power-law non-Newtonian viscosity model in OpenFOAM.

The temperature and velocity were considered constant and uniform for the jet inlet. Considering Figure 1, the heated part of impingement wall had a constant temperature, whereas adiabatic boundary condition was applied to the other walls. No-slip boundary condition was applied to all walls, and the flow was assumed to be fully developed at the outlets. Physical properties of working fluid are presented in Table 1.

\section{Results and discussions}

In order to evaluate the numerical results, variation of the local Nusselt number for impinging slot jet of air is compared with the results of Lee et al. [11] in Figure 2(a). This comparison shows good agreement between the present results and results of Lee et al.

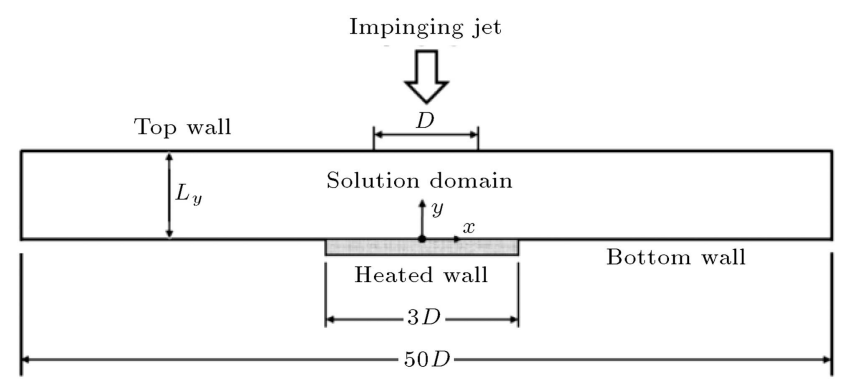

Figure 1. Schematic diagram of a two-dimensional confined impinging jet. studies. Moreover, Figure 2(b) illustrates the comparison of velocity profiles of the opposed impinging power-law fluids streams with results of Srisamran and Devahastin [18], approving the accuracy of numerical simulations with power-law model in OpenFOAM.

Figure 3 shows the flow pattern and dimensionless temperature distribution for impinging jet of shearthinning fluid with power-law index of $n=0.4$. This Figure illustrates the effect of Richardson number on

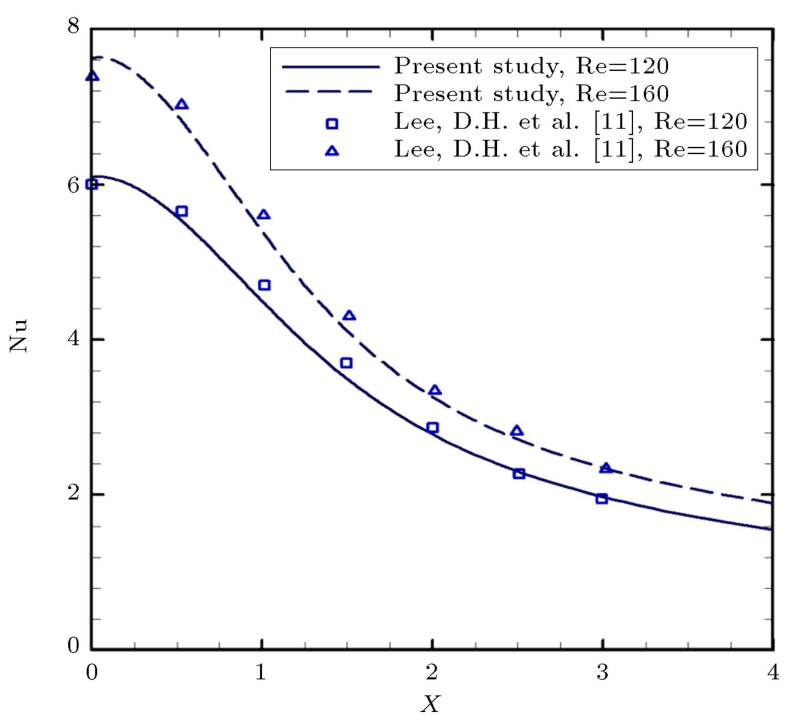

(a)

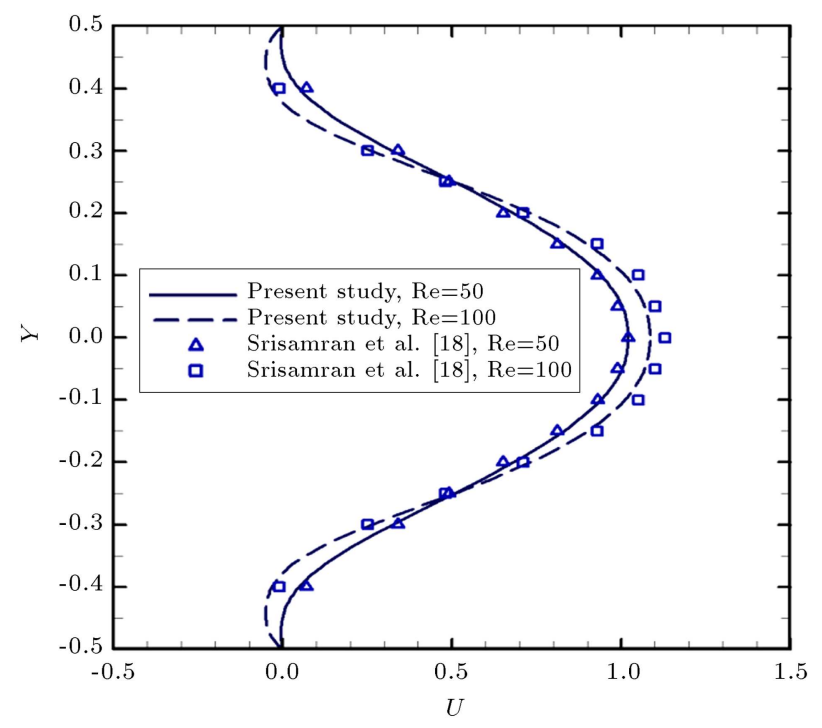

(b)

Figure 2. Comparison of: (a) local Nusselt number for impinging slot jet with $A_{y}=6$ and $\operatorname{Re}=120,160$, and (b) velocity profile for non-Newtonian opposed impinging streams with $n=0.6161, K=0.6572$, and $\operatorname{Re}=50$ and 100.

Table 1. Physical properties of working fluid.

\begin{tabular}{ccccc}
\hline $\boldsymbol{\rho}\left(\mathrm{kg} / \mathbf{m}^{\mathbf{3}}\right)$ & $\boldsymbol{C}_{\boldsymbol{p}}(\mathrm{kJ} / \mathrm{kg} . \mathbf{K})$ & $\boldsymbol{K}_{\boldsymbol{f}}(\mathrm{W} / \mathbf{m . K})$ & $\boldsymbol{K}\left(\mathbf{P a . s} \mathbf{n}^{\boldsymbol{n}}\right)$ & $\boldsymbol{n}$ \\
\hline 1000 & 4.1 & 0.7 & 0.00383 & $0.4-1.6$ \\
\hline
\end{tabular}




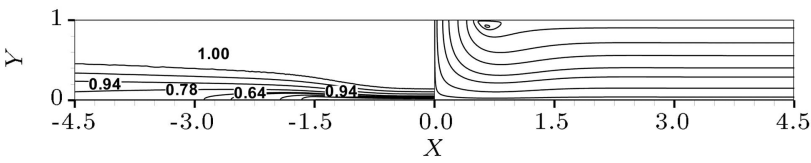

(a)

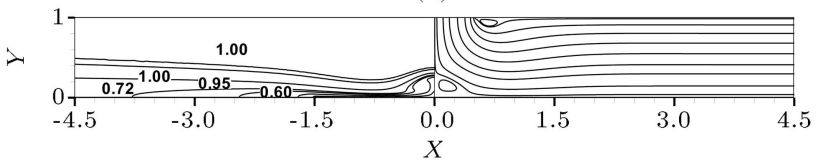

(b)

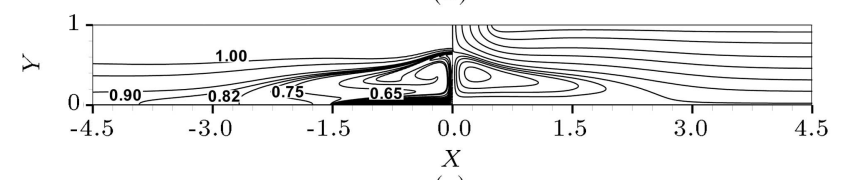

(c)

Figure 3. Flow pattern and dimensionless temperature distribution for impinging jets with $n=0.4, \mathrm{Pe}=1500$, and $A_{y}=1$ : (a) $\mathrm{Ri}=1$, (b) $\mathrm{Ri}=10$, and (c) $\mathrm{Ri}=25$.

$\mathrm{Pe}=1500$ and $A_{y}=1$. An increase in Richardson number corresponds to an increase in the temperature gradient in the vicinity of the bottom wall. Therefore, for high Richardson numbers, buoyancy forces dominate the inertial forces, and a recirculation zone is formed in the vicinity of the impingement wall. In other words, buoyancy force prevents impinging stream from reaching the hot wall. For $\mathrm{Ri}=25$, the flow reversal is more significant. The effect of vortices on temperature distribution in the vicinity of the bottom wall can be observed by the agreement of temperature distribution with stream lines. Figure 4 shows the dimensionless stream-wise velocity profiles for the impinging jet of shear-thinning, Newtonian and shear-thickening fluids with $\mathrm{Ri}=1$ and 25 at various horizontal positions. The results indicate that, for shear-thinning fluid, velocity variation is greater than the other fluids. The velocity profiles in the positions close to the stagnation point indicate the reverse flow of $\mathrm{Ri}=25$ for all of working fluids, clearly. For regions farther downstream, such as $X=4$, the velocity profiles are smooth and quite similar for all of fluids at $\mathrm{Ri}=1$ and 25 , due to flow development. These results show a similar trend to those reported by Chatterjee et al. [8] and Cavadas et al. [9].

Figure 5 shows the effect of Richardson number on vertical velocity profiles for various fluids at a vertical position of $Y=0.5$. For $\mathrm{Ri}=25$, the flow reversal is denoted by positive values of normal velocity in the central region. The velocity variation of shear-thinning fluids is larger than that of the other fluids due to shear-thinning fluids' lower resistance against the velocity gradients, which are developed by impinging and buoyancy streams. Distribution of the local Nusselt number for various fluids jets with different Richardson numbers is shown in Figure 6 . Gharraei et al. [19] showed that, for impinging jets of various fluids with the same inlet velocity and

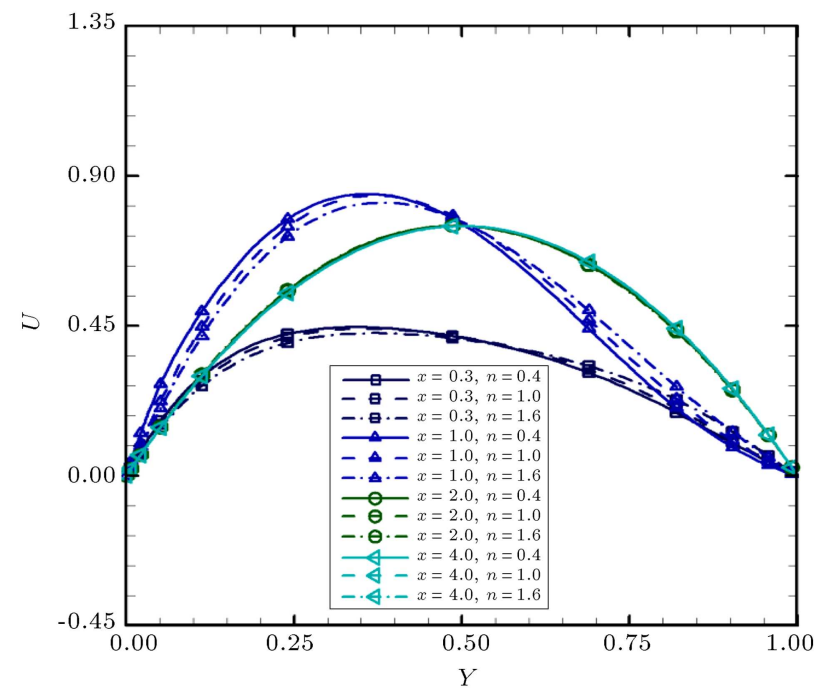

(a)

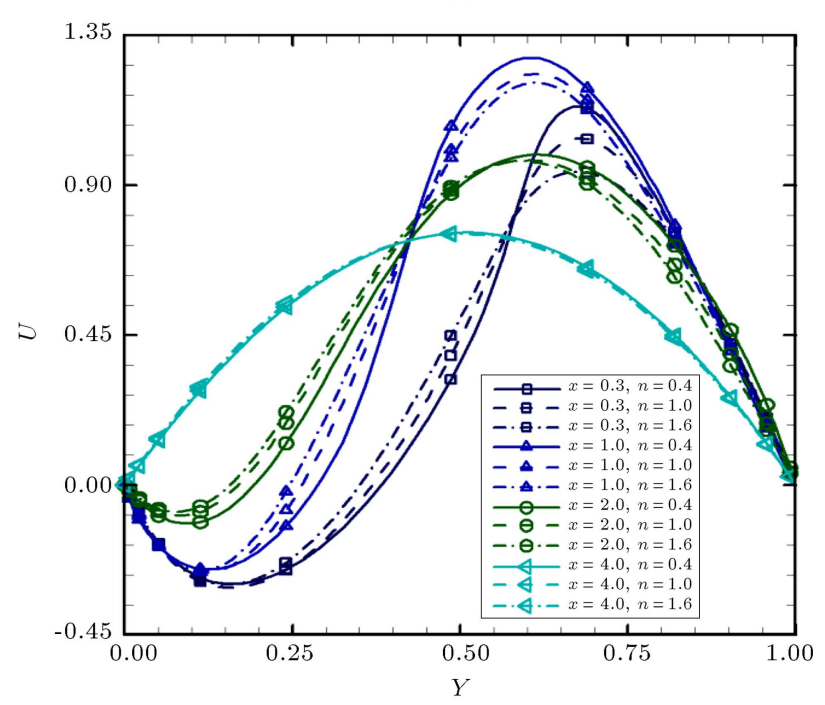

(b)

Figure 4. Dimensionless stream-wise velocity profiles for the jets of various fluids with $\mathrm{Pe}=1500, A_{y}=1$ : (a) $\mathrm{Ri}=1$ and $(\mathrm{b}) \mathrm{Ri}=25$.

consistency coefficient, the fluid with lower power-law index has a higher heat transfer coefficient. This is due to lower effective viscosity of these fluids in the region of high-velocity gradient and, consequently, further penetration of impinging streams into the boundary layer. Therefore, due to the lower effective viscosity of the shear-thinning fluids, by increasing the shear stress, the recirculation zone is formed in the vicinity of impingement wall; thus, the Nusselt number variations become higher than those of the other fluids. For $\mathrm{Ri}=1$ and 5 , the heat transfer rate depends on the direct penetration of jet stream into the boundary layer. Nevertheless, penetration of cold stream into the near wall region, by the reverse flow, changes the distribution of Nusselt number and increases the $\mathrm{Nu}$ for distances about $X=0.5$ and 1.5 for $\mathrm{Ri}=10$ and 25 , respectively. Moreover, for these cases, decreasing axial 
velocity in the vicinity of stagnation point decreases Nusselt number in this region.

Flow pattern and temperature distribution for jet-to-plate spacings of 0.6 and 0.3 are presented in

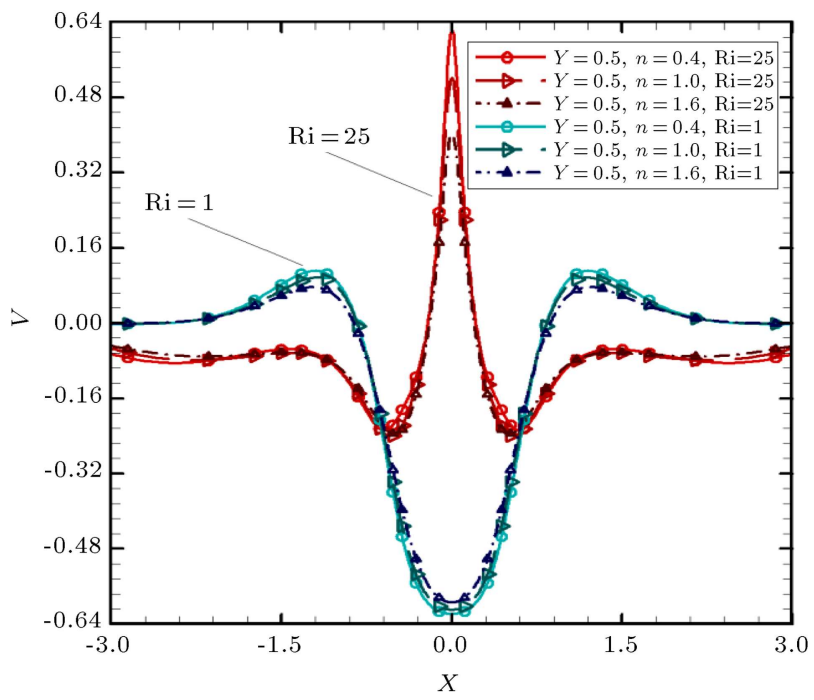

Figure 5. Dimensionless vertical velocity distribution for various fluids jets with $\mathrm{Pe}=1500, A_{y}=1, \mathrm{Ri}=1$, and 25; $Y=0.5$.

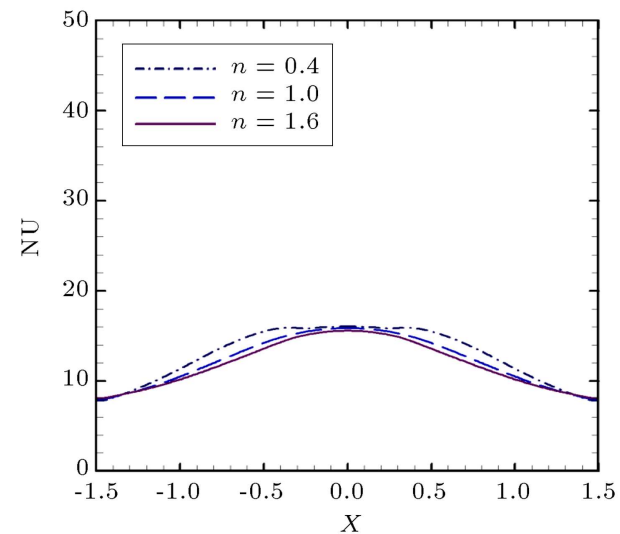

(a)

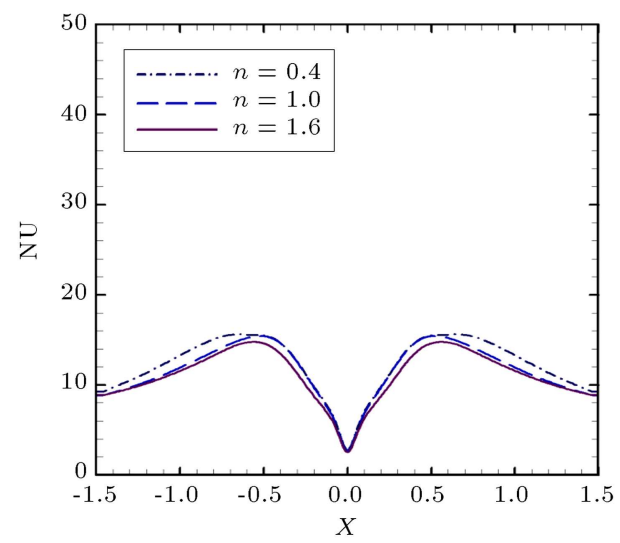

(c)
Figure 7 for various fluid jets with the same thermal boundary conditions as $\mathrm{Pe}=1500$ and $\mathrm{Ri}=25$. Decreasing the jet-to-plate spacing weakens the reverse flow in the vicinity of impingement wall; for $A_{y}=0.3$, reverse flow disappeared. In addition, due to the higher effective viscosity of shear-thickening fluids, the recirculation zone is not formed even for $A_{y}=0.6$. The vertical velocity distribution in the vicinity of the impingement wall $(Y=0.05)$ for the same cases as in Figure 7 is shown in Figure 8. The results illustrate that, for $A_{y}=0.6$, the flow reversal in the vicinity of impingement wall has a higher velocity of shearthinning fluid in comparison with those of other fluids due to shear-thinning fluids' lower resistance against the high velocity gradients.

Figure 9 illustrates the flow structure and temperature distribution of various fluids jets with different inlet Peclet numbers. In order to study the effect of inlet Peclet number on flow and heat transfer of impinging jet, the temperature difference between jet inlet and hot plate is kept constant and is equal to that of the case with $\mathrm{Pe}=1500$ and $\mathrm{Ri}=25$. For all of the cases, increasing the inlet Peclet number leads to the elimination of flow reversal due to the

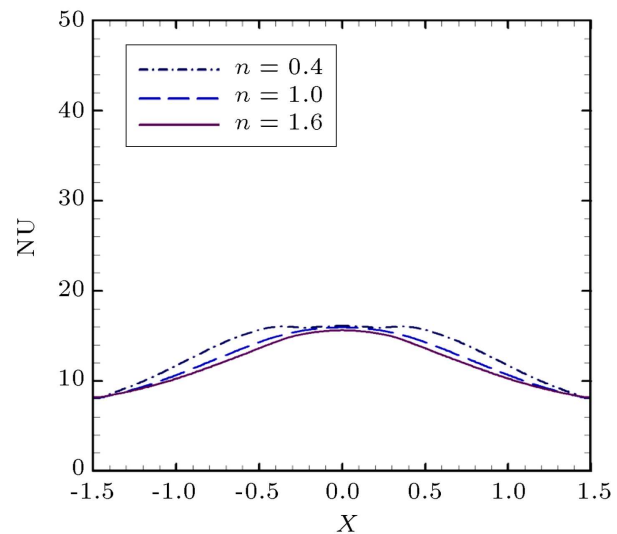

(b)

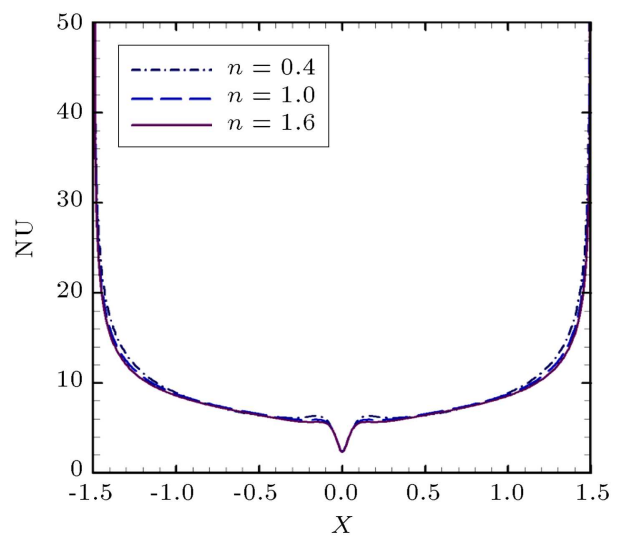

(d)

Figure 6. Distribution of the local Nusselt number on the impingement wall at $\mathrm{Pe}=1500, A_{y}=1$ for various fluids: (a) $\mathrm{Ri}=1$, (b) $\mathrm{Ri}=5$, (c) $\mathrm{Ri}=10$, and (d) $\mathrm{Ri}=25$. 


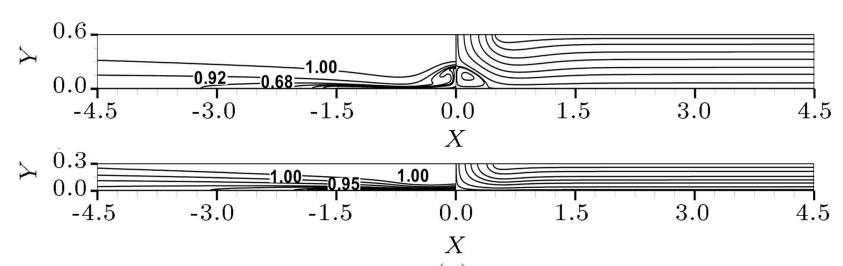

(a)

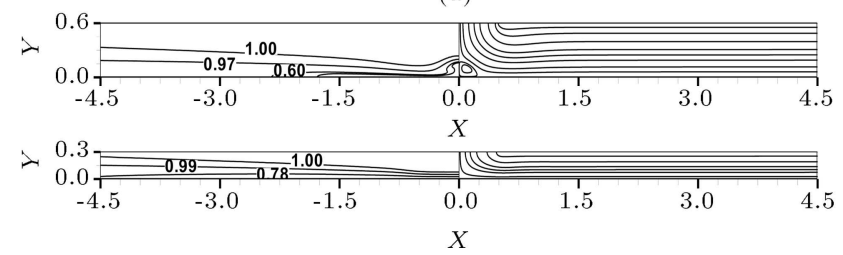

(b)

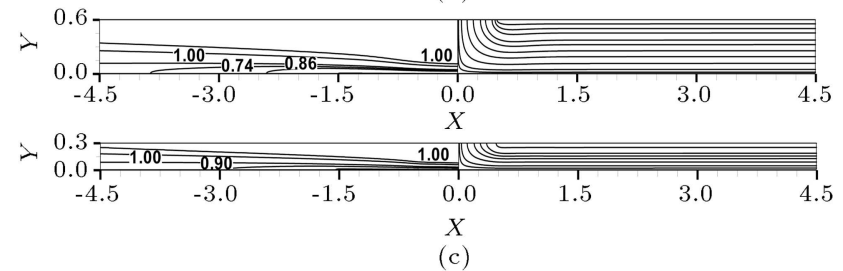

Figure 7. Flow pattern and dimensionless temperature distribution for jets of various fluid with $\mathrm{Pe}=1500$ and $\mathrm{Ri}=25:$ (a) $n=0.4$, (b) $n=1$, and (c) $n=1.6, A_{y}=0.6$ (top); $A y=0.3$ (bottom).

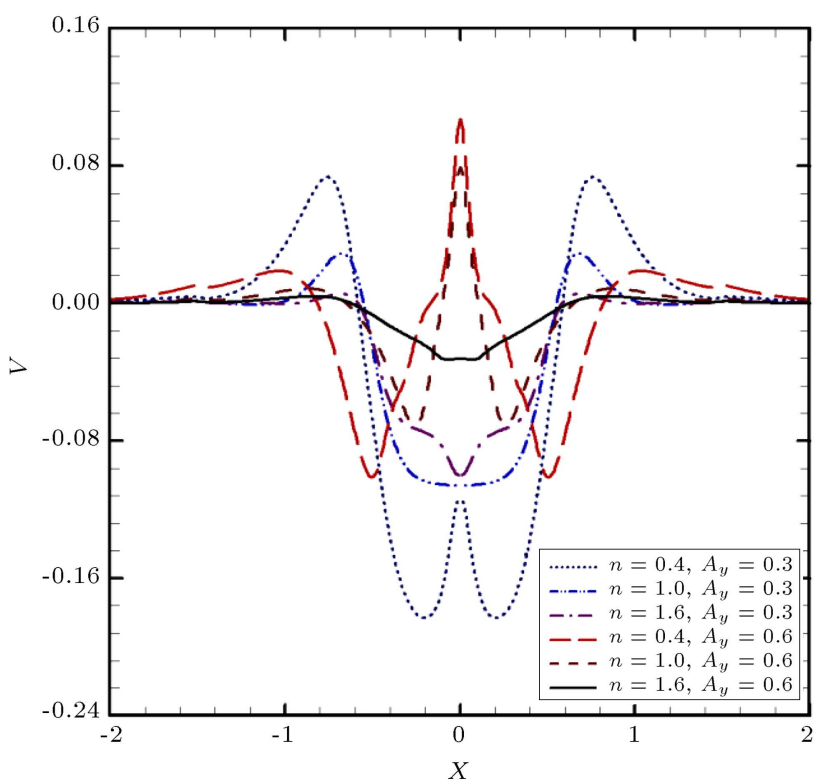

Figure 8. Dimensionless normal velocity profiles in the vicinity of impingement plate $(Y=0.05)$ for various fluids jets with $\mathrm{Pe}=1500$ and $\mathrm{Ri}=25 ; A_{y}=0.6$ and 0.3 .

increase of jet momentum flux. By increasing the inlet Peclet number for shear-thinning fluid, due to the higher momentum flux and higher shear stresses, larger vortices are created around the jet inlet. Furthermore, higher momentum flux of jet stream leads to its deeper penetration into the thermal boundary layer on the impingement wall and increases the heat transfer rate.

Figure 10 shows the effects of reducing the jet inlet

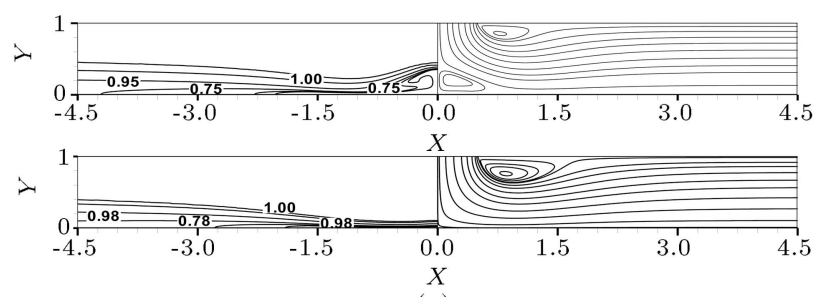

(a)
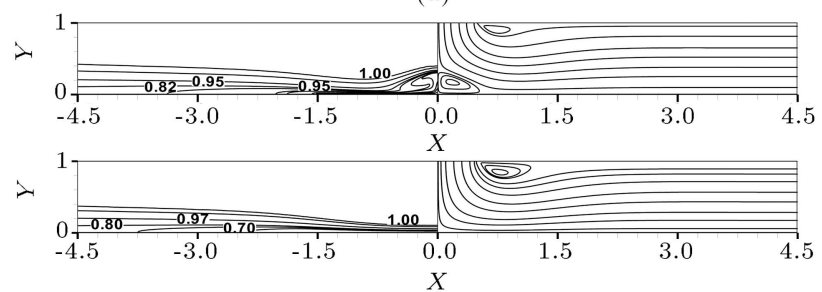

(b)
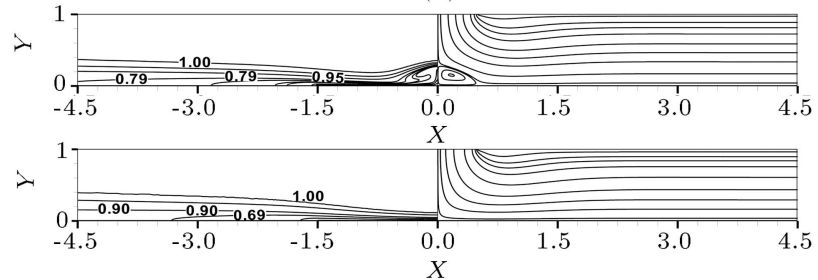

(c)

Figure 9. Flow pattern and dimensionless temperature distribution for jets of various fluids with the same thermal boundary conditions as $\mathrm{Pe}=1500$ and $\mathrm{Ri}=25$ : (a) $n=0.4$, (b) $n=1$, and (c) $n=1.6$. Pe $=2500$ (top) and $\mathrm{Pe}=3500$ (bottom).
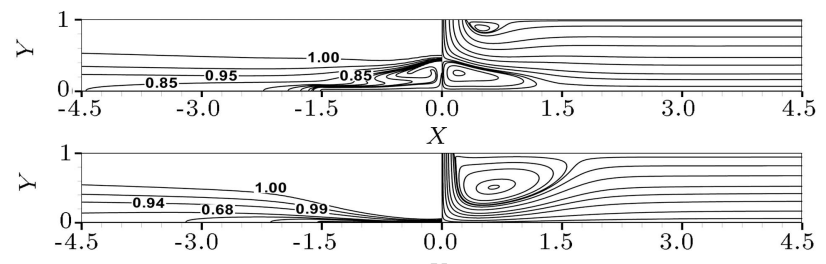

$X$
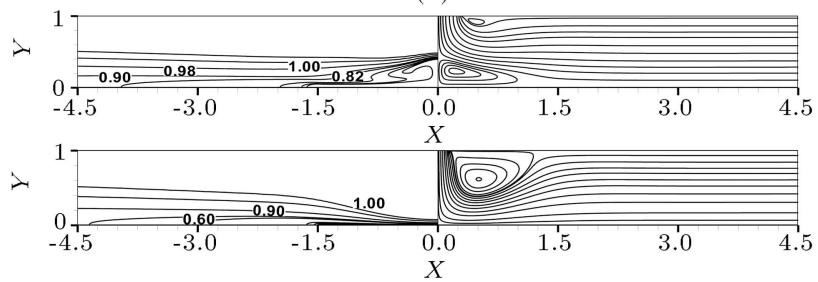

(b)

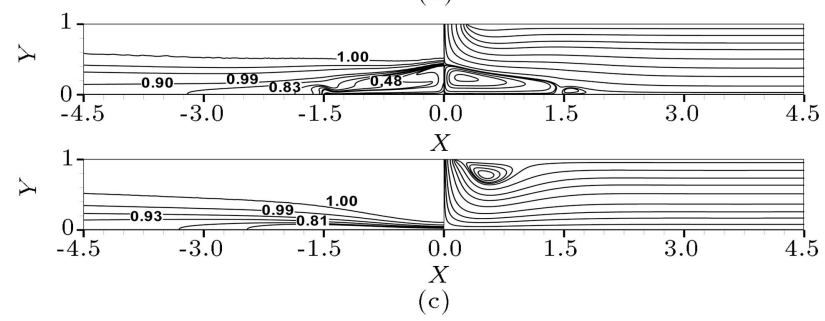

Figure 10. Flow pattern and dimensionless temperature distribution for jets of various fluids with the same boundary conditions as $\mathrm{Pe}=1500, \mathrm{Ri}=25$ and identical inlet flow rate: (a) $n=0.4$, (b) $n=1$, and (c) $n=1.6$. $D^{*}=0.6$ (top); and $D^{*}=0.3$ (bottom). 


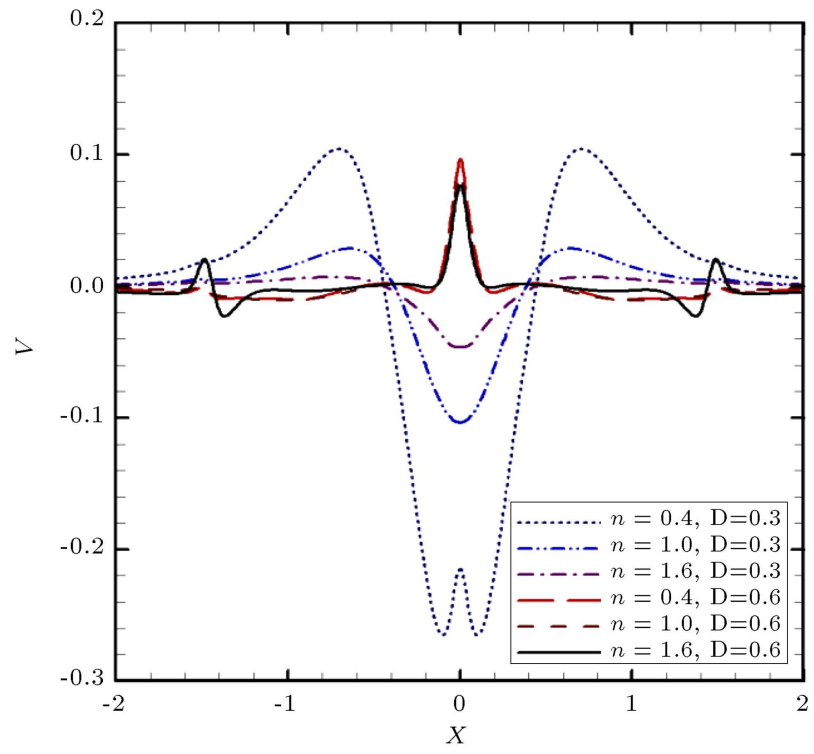

Figure 11. Dimensionless vertical velocity distribution in the vicinity of impingement plate $(Y=0.05)$ for various fluids jets with $\mathrm{Pe}=1500, \mathrm{Ri}=25$, and $D^{*}=0.6,0.3$.

width from 1 to 0.6 and 0.3 on the flow structure and temperature distribution for various power-law indices under the same thermal conditions as $\mathrm{Pe}=1500$, $\mathrm{Ri}=25$, and identical inlet flow rate. As the inlet width decreases to $D^{*}=0.6$, a small vortex is created in the vicinity of the impingement wall. Moreover, by reducing the inlet width to $D^{*}=0.3$, the reverse flow is vanished. For an impinging jet with the same conditions as shown in Figure 10, the vertical velocity distribution in the vicinity of the impingement wall $(Y=0.05)$ is shown in Figure 11. According to this figure, for shear-thinning fluid jet with $D^{*}=0.3$, the greater velocity variation is created due to lower resistance of this fluid against velocity gradients and higher penetration of jet stream into the boundary layer in the vicinity of stagnation point. Moreover, this figure illustrates the flow reversal in the central region for cases with $D^{*}=0.6$. Figure 12 shows the dimensionless stream-wise velocity profiles for the impinging jets with the same conditions as in Figure 10 at horizontal positions $X=0.3$, and 1 . As can be seen, for all of the fluids, in the positions farther from the stagnation point, the fully developed velocity profile is created. For shear-thinning fluid with $D^{*}=0.3$, the velocity variations are greater than other cases due to generation of large vortices near the jet inlet and concentration of momentum flux in the central region. Moreover, the recirculating flow in the vicinity of impingement plate is obvious for the cases with $D^{*}=0.6$.

In order to investigate the effects of variations in the jet-to-plate spacing, inlet Peclet number, and jet inlet width on the heat transfer characteristics, distribution of the local Nusselt number on the im-

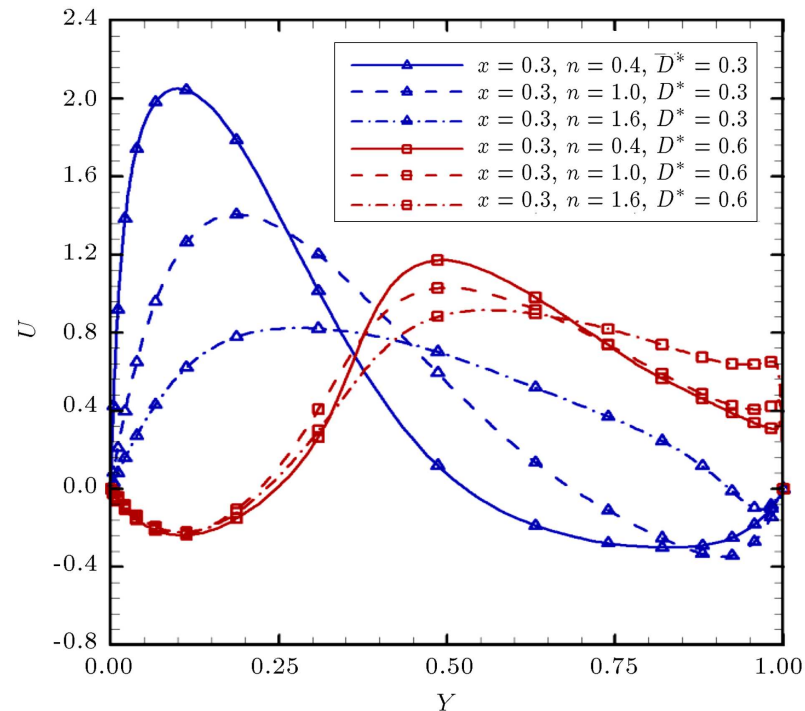

(a)

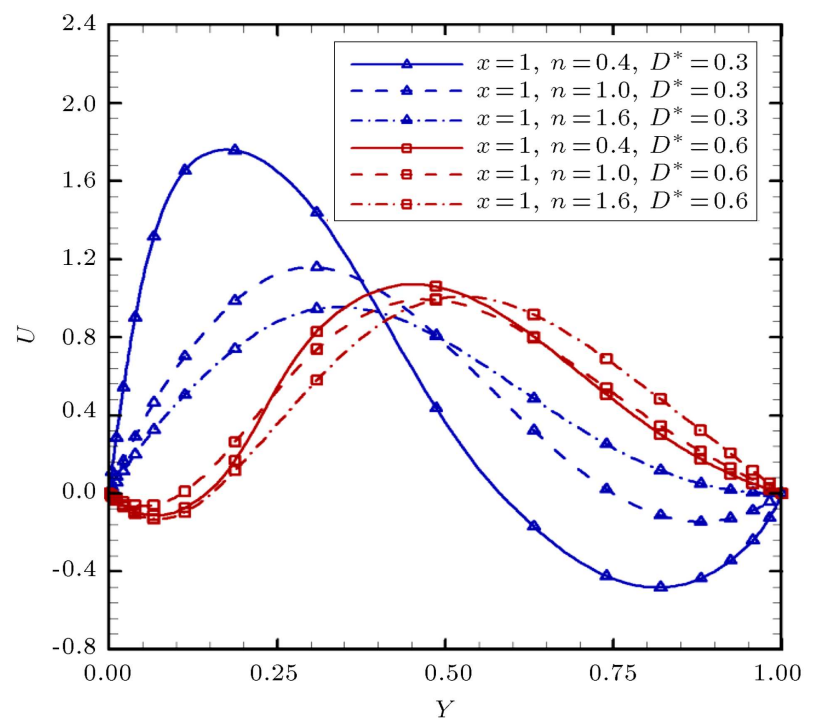

(b)

Figure 12. Dimensionless streamwise velocity profiles for various fluids jets with $\mathrm{Pe}=1500, \mathrm{Ri}=25, A_{y}=1$, and $D^{*}=0.6$ and 0.3 : (a) $X=0.3$ and (b) $X=1$.

pingement wall for various fluids is shown in Figure 13. This figure illustrates the effects of variation in the afore-mentioned parameters with constant temperature difference and flow rate the same as the case with $\mathrm{Pe}=1500$ and $\mathrm{Ri}=25$. This figure reveals that decreasing the jet-to-plate spacing from 1 to 0.6 and then to 0.3 , increasing the inlet Peclet number from 1500 to 2500 and then to 3500 , and reducing the inlet width from 1 to 0.6 and then to 0.3 can increase the local Nusselt number. On the other hand, Figure 13 follows Figures 8 and 11, illustrating vertical velocity distribution in the vicinity of impingement wall for different jet-to-plate spacings and inlet widths, respectively. For all of the cases, the increase in the downward vertical velocity in Figures 8 and 11 leads 


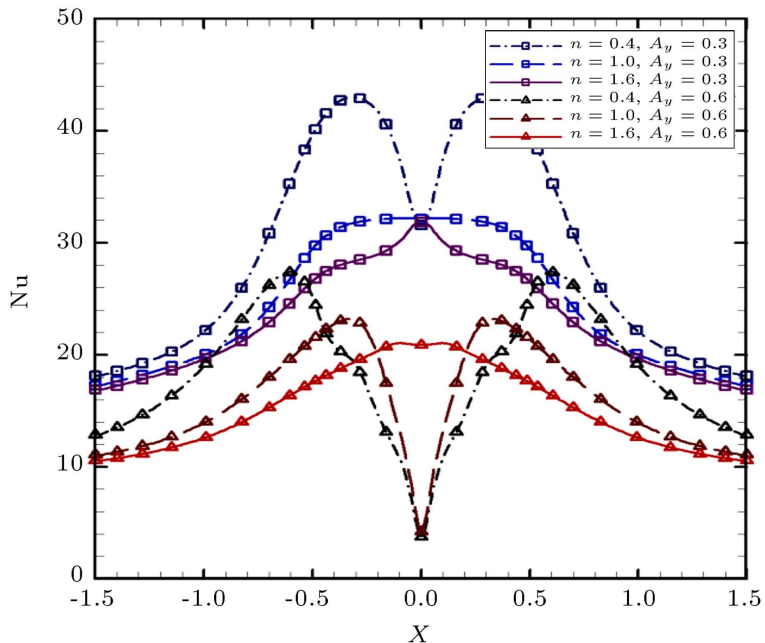

(a)

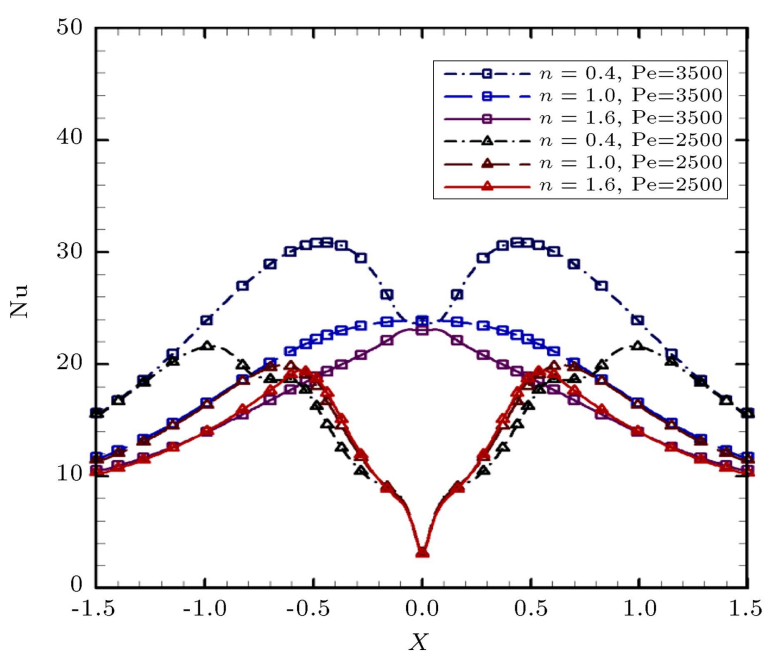

(b)

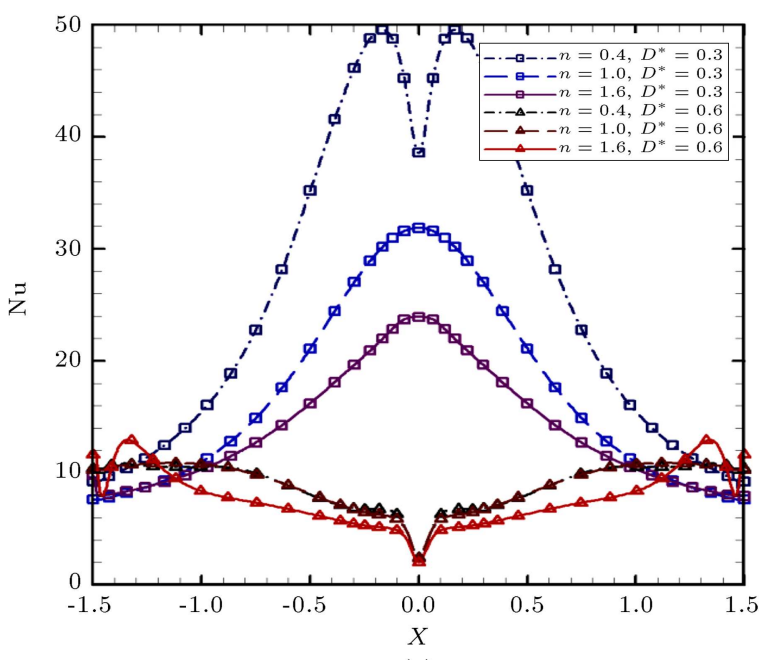

(c)

Figure 13. Distribution of the local Nusselt number on the impingement wall for various fluids jets with the same boundary conditions as $\mathrm{Pe}=1500, \mathrm{Ri}=25$ and identical inlet flow rate: (a) $\mathrm{Pe}=1500, \mathrm{Ri}=25, A_{y}=0.6,0.3$, (b) $\mathrm{Pe}=2500,3500$, and (c) $D^{*}=0.6,0.3$.
Table 2. The average Nusselt number for cases with higher local Nusselt numbers.

\begin{tabular}{lccc}
\hline & $\mathbf{P e}=\mathbf{3 5 0 0}$ & $\boldsymbol{A}_{\boldsymbol{y}}=\mathbf{0 . 3}$ & $\boldsymbol{D}^{*}=\mathbf{0 . 3}$ \\
\hline $\mathbf{N u _ { \text { avg } } , \boldsymbol { n } = \mathbf { 0 . 4 }}$ & 25.061 & 29.802 & 26.605 \\
$\mathbf{N u}_{\text {avg }}, \boldsymbol{n}=\mathbf{1 . 0}$ & 18.902 & 24.662 & 17.335 \\
$\mathbf{N u}_{\text {avg }}, \boldsymbol{n}=\mathbf{1 . 6}$ & 16.517 & 23.213 & 14.116 \\
\hline
\end{tabular}

to the increase of local Nusselt number in Figure 13, and flow reversal decreases the Nusselt number. For all of the mentioned cases, the highest local Nusselt number variation belongs to shear-thinning fluids due to the afore-mentioned reasons for the previous cases. Therefore, the maximum local Nusselt number belongs to shear-thinning fluid with $n=0.4$ and $D^{*}=0.3$. Table 2 presents the values of the average Nusselt number for all of the fluids, considering the cases whose flow reversal has been vanished. According to the results, the maximum average Nusselt number belongs to the flow of shear-thinning fluid with $n=0.4$ in the jet-to-plate spacing of 0.3 .

\section{Conclusions}

Hydrodynamic and thermal characteristics of nonNewtonian impinging slot jets in the mixed convection regime were investigated numerically. The simulation was performed using a temperature-dependent powerlaw viscosity model. The results showed that heat transfer rate for low Richardson numbers depends on the direct penetration of the jet stream into the boundary layer, but by increasing the Richardson number and generation of the recirculation zone, the flow reversal controls the Nusselt number distribution on the wall in the region close to stagnation point. It was also observed that, for the shear-thinning fluids, the velocity variations are larger due to the lower effective viscosity in the vicinity of wall and the further penetration of impinging streams into the boundary layer. Furthermore, by decreasing jet-to-plate spacing, increasing inlet Peclet number, and decreasing the inlet width, the reverse flow disappears in the vicinity of heated wall; however, increasing the jet penetration into the near wall region increases the local Nusselt number. Moreover, the results illustrated that the maximum local and average Nusselt number belong to the shear-thinning jets with minimum inlet width and minimum jet-to-plate spacing.

\section{Nomenclature}

$\begin{array}{ll}A_{y} & L_{y} / D \text { aspect ratio } \\ C_{p} & \text { Heat capacity of constant pressure } \\ D & \text { Jet width } \\ D^{*} & \text { Normalized reduced jet width }\end{array}$




$\begin{array}{ll}d & \text { Reduced jet width } \\ g & \text { Gravity } \\ h & \text { Heat transfer coefficient } \\ J & \text { Second invariant of the strain-rate } \\ & \text { tensor } \\ K & \text { Consistency factor } \\ K_{f} & \text { Thermal conductivity } \\ L_{x}, L_{y} & \text { Length in } x \text { and } y \text { directions } \\ n & \text { respectively } \\ P & \text { Power-law index } \\ q^{\prime \prime} & \text { Pressure } \\ T & \text { Local convective heat flux } \\ W & \text { Temperature } \\ u, v & \text { Velocity magnitude } \\ x, y & \text { Cartesian velocity } \\ X, Y & \text { Cartesian coordinates } \\ \mathrm{Gr} & \text { Dimensionless Cartesian coordinates } \\ \mathrm{Nu} & \text { Grashof number } \\ \mathrm{Pe} & \text { Nusselt number } \\ \mathrm{Pr} & \text { Péclet number } \\ \operatorname{Re} & \text { Prandtel number } \\ \mathrm{Ri} & \text { Reynolds number } \\ G r e h & \text { Richardson number }\end{array}$

Greek symbols

$\beta \quad$ Thermal expansion coefficient

$\rho \quad$ Density

$\theta \quad$ Dimensionless temperature

\section{Subscripts}

$\begin{array}{ll}w & \text { Wall condition } \\ \text { ref } & \text { Reference condition } \\ \infty & \text { Ambient condition }\end{array}$

\section{References}

1. Lin, Z.H., Chou, Y.J., and Hung, Y.H. "Heat transfer behaviors of a confined slot jet impingement", Int. J. Heat Mass Trans., 40, pp. 1095-1107 (1977).

2. Shi, Y.L., Rar, M.B., and Mujumdar, A.S. "Effect of Prandtl number on impinging jet heat transfer under a semi-confined laminar slot jet", Int. Comm. Heat Mass Trans., 30, pp. 455-464 (2003).

3. Lee, H.G., Yoon, H.S., and Ha. M.Y. "A numerical investigation on the fluid flow and heat transfer in the confined impinging slot jet in the low Reynolds number region for different channel heights", Int. J. Heat Mass Trans., 51, pp. 4055-4068 (2008).
4. Chiriac, V.C. and Ortega, A."A numerical study of the unsteady flow and heat transfer in a transitional confined slot jet impinging on an isothermal surface", Int. J. Heat Mass Trans., 45, pp. 1237-1248 (2002).

5. Cavadas, A.S., Pinho, F.T., and Campos, J.B.L.M. "Laminar flow field in a viscous liquid impinging jet confined by inclined plane walls", Int. J. Therm. Sci., 59, pp. 95-110 (2012).

6. Aldabbagh, L.B.Y. and Mohammad, A.A. "Mixed convection in an impinging laminar single square jet", ASME J. Heat Trans., 131, pp. 022201-1-7 (2009).

7. Poh, H.J. and Kumar, K. "Heat transfer from a laminar impinging jet of a power law fluid", Int. Comm. Heat Mass Trans., 31, pp. 241-249 (2004).

8. Chatterjee, A., Dhingra, S.C., and Kapur, S. "Laminar impinging jet heat transfer with a purely viscous inelastic fluid", Num. Heat Trans. A., 42, pp. 193-213 (2002).

9. Cavadas, A.S., Pinho, F.T., and Campos, J.B.L.M. "Laminar non-Newtonian impinging jet flow confined by sloping plane walls", J. Non-Newton. Fluid., 169(170), pp. 1-14 (2012).

10. Wang, Ch.Ch. and Chen, Ch.K. "Mixed convection boundary layer flow of non-Newtonian fluid along vertical wavy plates", Int. J. Heat Fluid Fl., 23, pp. 831-839 (2002).

11. Lee, D.H., Park, H.J., and Ligrani, Ph. "Milliscale confined impinging slot jets: Laminar heat transfer characteristics for an isothermal flat plate", Int. J. Heat Mass Trans., 55, pp. 2249-2260 (2012).

12. Kumari, M., Pop, I., and Takhar, H.S. "Freeconvection boundary-layer flow of a non- Newtonian fluid along a vertical wavy surface", Int. J. Heat Fluid Fl., 18, pp. 625-631 (1997).

13. Sivasamy, A., Selladurai, V., and Rajesh Kanna, P. "Jet impingement cooling of a constant heat flux horizontal surface in a confined porous medium: Mixed convection regime", Int. J. Heat Mass Trans., 53, pp. $5847-5855$ (2010).

14. Ostwald, W. "About the velocity function of the viscosity of disperse systems I" [Journal Ueber die Geschwindigkeitsfunktion der Viskosität disperser Systeme I], Kolloid-Zeitschrift, 36, pp. 99-117 (1925).

15. De Waele, A. "Viscometry and Plastometry", J. Oil \& Col. Chem. Assoc., 6, pp. 33-69 (1923).

16. Chhabra, R.P. and Richardson, J.F., Non-Newtonian Flow and Applied Rheology, Engineering Applications, 2nd Edn., Butterworth-Heinemann/IChemE, UK (2008).

17. Patankar, S.V., Numerical Heat Transfer and Fluid Flow, 1st. Edn., Hemisphere, USA (1980). 
18. Srisamran, Ch. and Devahastin, S. "Numerical simulation of flow and mixing behavior of impinging streams of shear-thinning fluids", Chem. Eng. Sci., 61, pp. 4884-4892 (2006).

19. Gharraei, R., Vejdani, A., Islami, S.B., and Davani.D., A.A. "Numerical investigation on the fluid flow and heat transfer of the non-Newtonian multiple impinging jets", Int. J. Therm. Sci., 104, pp. 257-265 (2016).

\section{Biographies}

Reza Gharraei received his BSc degree in Mechanical Engineering from University of Tabriz, Tabriz, Iran in 2001, MSc degree in Thermo-Fluid Engineering from Amirkabir University of Technology, Tehran, Iran in 2004, and PhD degree in Thermo-Fluid Engineering from University of Tabriz, Tabriz, Iran in 2010. Currently, he is an Assistant Professor at the Mechanical Engineering Department, Azarbaijan Shahid Madani
University, Tabriz, Iran. His research interests are twophase flow, electrohydrodynamics, non-Newtonian fluids flow, heat transfer, and fluid flow in microchannels.

Amir Vejdani received his BSc degree in Mechanical Engineering from Azarbaijan Shahid Madani University, Tabriz, Iran in 2012. Currently, he is a Technical Expert in Power System Department, ARYA Heavy Machinery, Tehran, Iran. His research interests are heat transfer and fluid flow studies on non-Newtonian fluids and industrial coolants.

Leila Sasani received her BSc degree in Mechanical Engineering from Azarbaijan Shahid Madani University, Tabriz, Iran in 2012, MSc degree in Thermo-fluid Engineering from Azarbaijan Shahid Madani University, Tabriz, Iran in 2014. Her research fields are heat transfer and fluid flow in microchannels and impinging micro-jets, nano-fluids and non-Newtonian fluids. 